\title{
Entre a bombacha e a camisa negra: notas sobre a ação do fascismo italiano e do integralismo no Rio Grande do Sul
}

João Fábio Bertonha*

Resumo - O presente artigo aborda a ação do fascismo italiano no Rio Grande do Sul entre 1922 e 1942, procurando compreender o processo pelo qual ele se inseriu na vida da regiẩo colonial italiana e o grau de resposta dessa comunidade aos apelos do regime de Mussolini. As relações do fascismo com a estrutura da Igreja Católica na regiẫo e com o Integralismo sẩo especialmente enfocadas.

Abstract - This article seeks to analyse Italian Fascism's action in the state of Rio Grande do Sul between 1922 and 1942. The main purpose of the paper is to understand how Fascism tried to control the old Italian colonial zone and how the immigrants saw this effort. The fascists' relationship with the "integralistas" and the Catholic Church is especially stressed.

Palavras chave - Fascismo - Italianos - Rio Grande do Sul.

Key words - Fascism - Italians - Rio Grande do Sul.

Desde os inícios de suas atividades, o Partido fascista (e depois, o governo fascista) procurou transferir seus ideais para seus concidadãos residentes no exterior. Nesse sentido foi feito todo um esforço no sentido de manter viva a italianidade entre os imigrantes e seus des-

* Doutor em História Social/UNICAMP.

Estudos Ibero-Americanos. PUCRS, v. XXIV, n. 2, p. 247-268, dezembro 1998 
cendentes e de inculcar a ideologia fascista entre eles, de forma a manter os laços entre as comunidades italianas espalhadas pelo mundo e a Itália fascista

Esse esforço atingiu todos os países de imigração italiana e o Brasil não fugiu a regra. ${ }^{1}$ Desde 1923 , de fato, começaram os esforços fascistas para cativar os italianos e seus descendentes residentes no país. Foi principalmente a partir de 1928 , porém, com a chegada dos cônsules "fascistas" ao Brasil, que os esforços fascistas foram redobrados, com todos os meios sendo empregados na tarefa de cativar os imigrantes.

E que meios seriam estes ${ }^{2} \mathrm{Na}$ realidade, o fascismo se serviu de duas vias principais para a busca do consenso no seio da comunidade italiana. De um lado, procurou-se fazer uma penetração direta nesta comunidade através da expansão da rede consular e da implantação de órgãos fascistas propriamente ditos: os "fasci all'estero", os "Dopolavoro", etc.

Ao mesmo tempo em que implantava seus instrumentos de propaganda e doutrinação no Brasil, o fascismo italiano ia agindo por outras vias no esforço supremo de conquistar as mentes e as almas dos italianos residentes no país. Nesse sentido, os consulados italianos foram agindo, no decorrer de todos os anos 20 e 30, com a intenção de controlar todos os órgãos que davam vida à assim chamada "colônia italiana". Escolas, jornais, associações, todos esses órgãos foram caindo um após o outro sobre o controle do fascismo, que os transformava em novos instrumentos para a difusão dos valores do regime.

Uma grande estrutura de propaganda foi, assim, montada, a qual dedicou-se com vontade à tarefa de difundir o fascismo no Brasil. Uma avaliação mais segura do sucesso dessa campanha entre os italianos e entre os brasileiros ainda está sendo desenvolvida, mas não resta dúvida de que a ação do fascismo italiano em território nacional foi bastante apreciável, merecendo uma atenção maior da historiografia que, até agora, dedicou-se apenas marginalmente ao tema.

Um grande trabalho de pesquisa sobre a ação do fascismo e do antifascismo italianos no Brasil está em vias de conclusão pelo autor,

1 Para os objetivos da ação do fascismo italiano entre as coletividades italianas do exterior em geral e, especialmente, para o Brasil, ver Bertonha (1997a e 1997b).

2 Um verdadeiro manancial de informaçôes sobre a ação fascista no Brasil pode ser localizado em Trento (1989, p. 267-404). 
o qual espera, com este trabalho, dar uma contribuição relevante ao estudo do tema. À parte outras dificuldades, porém, o trabalho com esta temática em termos brasileiros esbarra numa dificuldade típica dos países continentais: a amplitude geográfica, com a conseqüente formação de um sem número de realidades regionais.

$\mathrm{Na}$ realidade, a historiografia internacional sobre o tema já revelou como a absorção das variantes regionais dentro de cada país só enriquece a análise global. Isso ocorre, por exemplo, nas historiografias canadense e australiana quando se discutem as especificidades de Toronto e Quebec ${ }^{3}$ ou de New Walles e Queesland ${ }^{4}$ e, especialmente, na francesa, onde os estudos regionais sobre a questão do fascismo e os imigrantes italianos são extremamente ricos e numerosos. ${ }^{5}$

O caso que mais se aproxima do brasileiro, contudo, é o americano, onde as dimensões continentais do país (equivalentes às brasileiras) permitiram imensas variações entre comunidades italianas espalhadas em pontos diversos (e com inserções sociais, étnicas e outras diferentes em cada contexto) do território americano. Nesse sentido, é possível notar grandes diferenças, por exemplo, entre a esmagadora maioria dos italianos vivendo nas grandes cidades da costa Leste como trabalhadores manuais (Bayor, 1978; Cannistraro, 1975; Nelli, 1970; Cicolella, 1986) e as comunidades menores, mais bem sucedidas economicamente e, aparentemente, mais ligadas ao fascismo justamente por isso, da Califórnia e da Costa Oeste em geral (Cinel, 1987; Gumina, 1978; Salvetti, 1982). Um estudo sistemático dos trabalhos monográficos sobre as diversas coletividades italianas espalhadas pelos Estados Unidos certamente levantaria outras particularidades regionais relevantes, como certos estudos (Mormino, 1986 e 1987) já indicam.

A situação brasileira é realmente semelhante à americana. De fato, a coletividade italiana no Brasil pode ser dividida, grosso modo, em três grandes blocos: pequenos agricultores vivendo no regime de pequena propriedade no sul do país; trabalhadores rurais e, cada vez

3 Sobre Toronto, ver Harney (1981 e 1984) e Zucchi (1988). Sobre o Quebec, ver Perin (1981) e Ramirez (1988).

4 Ver Cresciani (1984); Meneghetti (1982) e O'Connor (1996).

5 A historiografia francesa produziu uma enormidade de trabalhos sobre a questão dos italianos e o fascismo nas mais diversas regiões do país. Particularmente interessantes são os trabalhos de Ralph Schor sobre a região dos Alpes Marítimos franceses. Ver Schor $(1984,1986,1988,1988$ a e 1994). 
mais, urbanos residentes no estado e, especialmente, na cidade de São Paulo ao lado de uma elite industrial e de uma nascente classe média e um pequeno grupo de artesãos e comerciantes residindo nas grandes capitais do Norte e Nordeste e no Rio de Janeiro.

Esse texto procura fornecer subsídios para a análise do tema em um contexto particular: o sul do Brasil e, em particular, o Rio Grande do Sul. Uma análise aprofundada sobre a questão seria impossível, pois implicaria numa pesquisa bem maior nas fontes locais, o que é inviável para o autor. Ainda assim, entendemos que o conjunto de informações aqui apresentadas pode estimular pesquisas locais de maior fôlego que certamente irão ampliar nosso conhecimento sobre o tema. É nesse sentido que esse artigo foi escrito.

\section{O Paraná e Santa Catarina}

Os estados do Sul eram a segunda maior concentração de italianos no território brasileiro depois da de São Paulo. No Paraná, por exemplo, existiam cerca de 50 mil italianos e descendentes por volta de $1942,{ }^{6}$ e sabemos que as agências consulares, os fasci all'estero e os Dopolavoro distribuíam material de propaganda a italianos e brasilei$\operatorname{ros}^{7}$ e que até um busto de Mussolini foi inaugurado em Curitiba em $1938^{8}$.

É num relatório de $1935^{\circ}$, contudo, que podemos determinar melhor o que ocorria em Curitiba e em outras áreas italianas do estado. Nesse sentido, o Consulado italiano mantinha, em seu sistema de propaganda, três eixos-chave:

6 National Archives at College Park (NACP)/Records of the Office of War Information, RG 208, 208/350/71/12/34, Box 437, relatório "Strategic Survey of South Brazil" de 11/8/1942, p. 2.

7 Vide Archivio Centrale dello Stato/Ministero della Cultura Popolare, Divisione Generale di Propaganda (ACS/MinCulPop, DGP), b. 272, f. 10, sottof. 3, p. "Propaganda italiana a Curitiba", diversos documentos e Idem, b. 273, f. 10, sottof. 5, p. "Fascio a Curitiba", diversos documentos.

8 Vide ACs/MinCulPop, DGP, b. 273, f. 10, sottof. 6, p. "Manifestazioni varie Brasile", Appunto MinCulPop de 10/5/1938.

9 ACs/MinCulPop, DGP, b. 272, f. 10, sottof. 3, p. "Propaganda italiana a Curitiba", relatório Consulado de Curitiba, 25/6/1936. 
- Italianos: cursos na Dante, comemorações e reuniões do fascio, folhetos e jornais.

- Descendentes de italianos: cursos de italiano na Dante, na Universidade e no Colégio das irmãs do Sagrado Coração de Jesus, curso de ginástica e filmes, bailes, passeios, etc.

- Brasileiros: cursos de italiano na Universidade e conferências literárias e políticas na mesma; curso de italiano no Centro de Cultura Feminina de Curitiba e no Colégio das irmãs do Sagrado Coração de Jesus, rubrica italiana nos "Diários", rádio italiana.

Há também informações sobre antifascistas isolados em pequenas cidades do interior do estado, de forte resistência contra os fascistas na Società Dante Alighieri de Ponta Grossa em 1929/31 (Trento, 1989 , p. 332) e ainda em $1937^{10}$ e preocupações fascistas com um "aguerrido núcleo antifascista no Paraná chefiado por Francesco Stobbia" em 1928. ${ }^{11}$ Fragmentos de uma realidade que uma boa pesquisa de história local poderia desvendar por completo.

Sobre Santa Catarina, onde os cerca de 10 mil italianos e descendentes eram grandemente minoritários frente aos alemães e aos teutobrasileiros, temos notícias de ao menos 3 sociedades italianas funcionando no estado em 1927 (Fratellanza italiana em Florianópolis; San Marco em Nova Venezia e a Dante Alighieri de Porto União, essa última antifascista),${ }^{12}$ de dificuldades para a chegada dos filmes italianos em Florianópolis ${ }^{13}$ e de alguma distribuição de material de propaganda, para brasileiros e italianos, no estado pelos organismos diplomáticos italianos, o que não é tão relevante.

Felizmente, porém, dispomos do relatório do Vice-Cônsul de Florianópolis, Guido Zecchin, enviado ao Ministero degli Affari Esteri

10 Archivio Centrale dello Stato/Casellario Politico Centrale (ACS/CPC), b. 1050, p. 134833, ('Capra, Giuseppe"), Telexpresso do MAE de 12/6/1937.

11 Ver Archivio Centrale dello Stato/Ministero dell'Interno, Divisione Generale di Pubblica Sicurezza, (ACS/MinInt, DGPS), Divisione Affari Generali e riservati, 1927, b. 190, p. "Movimento Antifascista - Brasile 1928", Informe Consulado de Curitiba, 7/2/1928.

12 ASMAE/MinCulPop, b. 67, p. "Italica", diversos documentos.

13 ACs/MinCulPop, DGP, b. 272, f. 10, sottof. 3, "Propaganda italiana a Curitiba", Informe Consulado de Curitiba, 18/2/1935. 
em $31 / 5 / 1935^{14}$ e que contém preciosas informações sobre os italianos de Santa Catarina, documento este que convém apresentar em detalhes.

Segundo Zecchin, os italianos de Santa Catarina viviam quase todos na zona rural como pequenos proprietários, sendo de pouca cultura e instrução e com ligações apenas sentimentais com a Itália. A segunda geração já se sentia brasileira, mas com algum sentimento filoitaliano, enquanto a terceira geração só se identificava com o Brasil. ${ }^{15}$ A difusão cultural italiana seria nula, enquanto as associações e escolas seriam quase inexistentes.

$\mathrm{O}$ autor se queixava amargamente sobre as dificuldades para difundir o fascismo entre essa colônia de camponeses e onde não havia uma classe dirigente italiana ligada à Pátria que pudesse apoiar esse esforço como em São Paulo. No máximo, o que havia era um ou outro advogado ou industrial (como o doutor Caruso, de Urussanga, que sempre apoiava o fascismo local) e os sacerdotes que, com medo das autoridades eclesiásticas brasileiras, pouco faziam, sempre segundo Zecchin, para difundir a italianidade, o que era totalmente insuficiente.

Existiam quatro fasci all'estero no estado (Urussanga, Nova Veneza, Laguna e Maleiro), que teriam sido fundados por idealistas e absorvido certo número de inscritos. Numa colônia rural (onde os colonos falavam dialeto e recebiam notícias fragmentárias da Itália) e sem pessoas de mais cultura para cuidar dos fasci all'estero, contudo, a difusão do fascismo era virtualmente impossível, o que desagradava visivelmente Zecchin, que sugeria medidas para tentar corrigir o problema.

Ele também fazia referência ao Integralismo, ressaltando como muitos filhos e netos de italianos se dirigiam ao mesmo, o que parece indicar como a propaganda italiana, apesar de não conseguir atrair os italianos em massa para o fascismo, gerou uma certa simpatia geral e difusa pelo mesmo e que parece ter tido algum papel na boa imagem do Integralismo entre os filhos e netos dos colonos italianos. A força

\footnotetext{
14 Idem, p. "Colletività italiana nello stato di Sànta Catarina".

15 O fato da colônia italiana ter se formado máis cedo no sul do país que em São Paulo, por exemplo, indica que essa possibilidade de, no Sul do país, termos que lidar não apenas com os italianos e seus filhos, mas também com seus netos, é bastante real.
} 
de questões tipicamente locais (e não relacionadas diretamente com a etnia), como os conflitos "planalto X litoral" e "elite luso brasileira X imigrantes” (Gertz, 1987, cap. 4) nessa atração dos filhos de italianos de Santa Catarina pelo Integralismo não pode, porém, ser esquecida, o que novamente revela que as propostas de René Gertz (1987) de que há mais elementos a serem considerados nas relações dos filhos dos imigrantes alemães e italianos com o Integralismo além da etnia são realmente válidas.

\section{O Rio Grande do Sul}

O Rio Grande do Sul era, dada a imensa coletividade italiana, lugar privilegiado para a propaganda fascista. De fato, apesar de nada indicar, na documentação consultada, que houvesse, como quer Giron (1994, p. 140-141), um plano efetivo de conquista da região pela Itália, não resta dúvida de que, após São Paulo, era no Rio Grande do Sul que estava o ponto focal da atividade fascista italiana no Brasil, o que indica a necessidade de investigarmos com mais cuidado o caso gaúcho.

A rede de propaganda fascista no Rio Grande do Sul tinha como centro, obviamente, Porto Alegre, mas se estendia também ao interior do estado. Aparentemente, ainda no final dos anos 20, a estrutura fascista estava pouco organizada no estado, a ponto de italianos de convicção fascista escreverem ao Ministero degli Affari Esteri se queixando da pouca difusão da ideologia fascista no Rio Grande do Sul e da mediocridade dos fasci all'estero locais. ${ }^{16}$ Também a difusão dos mesmos era pequena nos anos 20, começando com uma seção em Caxias em 1923 (GIRON, 1994: 84) e outra em Porto Alegre em $1926^{17}$ e atingindo apenas três localidades (Porto Alegre, Caxias e Pelotas) em 1927 (Ministero, 1928). Foi necessário esperar até o meio dos anos 30 para que os fasci all'estero atingissem sete cidades (Caxias, Porto Alegre, Pelotas, Uruguaiana, Rio Grande, Garibáldi e Bento Gonçalves - Gagliardetti, 1934, p. 9).

16 Archivio Storico Ministero degli Affari Esteri (ASMAE)/Affari Politici 1919-1930 (Brasile), b. 905, p. 1642, carta de Enrico Biasotti, fins de 1927.

17 Public Record Office, Foreign Office (PRO, FO) 371/11967, A 2932, relatório "Brazil - Annual report 1926" de 1927. 
O real desenvolvimento da atividade fascista no estado só começou, de fato, a partir da chegada do cônsul Manfredo Chiostri em Porto Alegre em 1926. A este diplomata teriam sido atribuídos, pelo governo italiano, "poderes absolutos para erradicar o velho espírito existente e expor as idéias do novo regime" e ele agiu a contento para difundir a ideologia do regime e controlar a vida dos italianos presentes no estado. ${ }^{18}$

Em 1929, Chiostri foi substituído pelo cônsul Mario Carli, o qual conseguiu grandes trunfos no seu trabalho de conversão da comunidade italiana do Rio Grande do Sul e, especialmente, da de Porto Alegre. Dentre estes, podemos citar a criação de um periódico fascista (La Nuova Italia), ${ }^{19}$ o subsídio para a tradução de obras italianas para o português, o aumento das atividades culturais e de ensino (inclusive pela cooptação da seção da Società Dante Alighieri da capital $^{20}$ ), a criação de um clube esportivo (Campo Sportivo Italo Balbo) em Porto Alegre e de colônias de férias no litoral (O Campeggio Mussolini) para socializar fascisticamente as crianças e jovens italianos locais, etc.

Carli também teria conseguido, sempre segundo a documentação americana, reorganizar as escolas italianas da capital e do interior e fascistizá-las, substituir os agentes consulares no interior do Rio Grande do Sul por fascistas e ampliar as atividades culturais e de ensino do italiano voltadas aos brasileiros. As associações não teriam aceitado se submeter totalmente ao Consulado, mas sua dependência financeira ao mesmo teria garantido sua adesão ao consenso fascista.

O Cônsul que seguiu Carli, Guglielmo Barbarisi, era um velho diplomata de carreira e, sob sua fraca direção, grande parte da atividade fascista cessou. O cônsul que chegou em 1937, Magno Santovicenzo, tentou reativar essa máquina clandestinamente e procurou reforçar

18 Quando não mencionado de forma diversa, as informações a seguir vem de Arquivo Diplomático Americano (ADA), Rolo 4/380, código 832.00F, relatório "Italian Activities in Brazil" de 6/2/1939, fotograma 19, p. 63-80.

19 Sobre esse jornal, que durou vários anos, ver ACS/MinCulPop, DGP, b. 272, f. 10, sottof. 2, p. "La Staffeta Rio Grandense di Garibaldi", informe Consulado italiano de Porto Alegre, 6/6/1934.

$20 \mathrm{ACs} / \mathrm{MinCulPop}, \mathrm{DGP}$, b. 272, f. 10, sottof. 2, p. "La Dante Alighieri in Brasile", diversos documentos. 
(sem êxito, aparentemente) a propaganda dirigida aos brasileiros, ${ }^{21}$ mas seus esforços foram dificultados, segundo a documentação americana de 1939, pelas leis nacionalistas brasileiras de 1938.

Tal esforço fascista, como se percebe, era concentrado em Porto Alegre. Ele também se dirigiu, porém, ao interior do estado, como o disseminar-se da rede dos fasci all'estero e dos Dopolavoro e a conquista de escolas e de associações como a Società di Mutuo Soccorso de Caxias do Sul (Histórias, 1988, p. 26-27) e a manutenção de um nível inédito de atividades culturais e recreativas promovidas pelo governo de Roma na região colonial italiana do interior do Estado (Giron, 1994, p. 110-112) podem comprovar.

Determinar em que grau os italianos do Rio Grande do Sul foram atingidos pela propaganda fascista é tarefa que requer alguns cuidados metodológicos capazes de absorver a multiplicidade de grupos e divisões entre os imigrantes italianos. De fato, fica evidente, a partir dos trabalhos de Loraine Giron (1986 e 1994), como, apesar do grau de diferenciação social entre os italianos do Rio Grande do Sul (e, especialmente, os do interior do estado) ser muito menor que entre os de São Paulo, também a zona colonial gaúcha desde cedo se organizou em classes e que era impossível que tal evolução não se refletisse na apreciação dessas pessoas ao fascismo.

Nesse sentido, a autora é explícita ao identificar uma fortíssima penetração do fascismo italiano entre a assim chamada burguesia regional (que formava a base dos fasci all'estero e que, na definição de Giron, incluiria não apenas os industriais, mas também os comerciantes e os profissionais liberais), enquanto as classes médias (pequenos industriais, comerciantes e artesãos) teriam se tornado integralistas e os (poucos) operários teriam recusado a mensagem de ambos os movimentos.

Essa proposta de Giron parece refletir a realidade e se aproxima de nossas reflexões sobre São Paulo e o resto do país, as quais também identificam na burguesia e na classes médias o grande público fascista. Ainda assim, sua análise apresenta diversos problemas, como a falta de uma definição mais precisa dos limites entre a "burguesia regional" e as "classes médias" e um enfoque rigidamente marxista ao

21 Ver ACs/MinCulPop, DGP, b. 273, f. 10, sottof. 5, p. "Diffusione del libro italiano nel Rio Grande do Sul", diversos documentos de 1937 e b. 278 , f. 14, sottof. 1, p. "Brasile - Propaganda italiana", relatório do Consulado de Porto Alegre de
24/8/1938. 
tentar explicar o porquê da burguesia regional aderir ao fascismo, o que a leva a reduzir todas as motivaçóes desse grupo a "interesses econômicos". Tal posicionamento também a faz considerar a ação fascista como algo não relacionado à luta social da região, o que não é cem por cento correto, pois a matriz fascista italiana vinha, sem dúvida, da realidade italiana, mas era vivida e reelaborada no contexto local, o que, dentro de certos limites, a incorporava à vida política e social da região. Os contatos dos fascistas locais com partidos gaúchos como o Partido Republicano Liberal (Giron, 1994, p. 114-115) apenas confirmam isso.

O principal problema das teses de Giron, porém, é que elas não conseguem estabelecer uma explicação razoável para a dicotomia "burguesia regional = fascista; classes médias = integralistas" que ela identificou, se limitando a análises classistas rigidíssimas, de difícil comprovação empírica e que deixam o leitor na dúvida se ela realmente se deu e, em caso afirmativo, sobre o porquê.

Parece fundamental, antes de mais nada, verificar se essa divisão entre os movimentos fascista italiano e integralista era tão rígida como propõe Giron, o que não parece provável. De fato, temos alguns indícios de colaboração entre fascistas italianos e integralistas no Rio Grande do $\mathrm{Sul}^{22}$ e a própria Giron (1994, p. 95-96 e 108) identifica momentos de ação mútua e de relações de base entre eles, o que flexibiliza um pouco a questão e nos permite perceber a fluidez e a ambigüidade de lealdades (fascista e integralista; brasileiro e italiano) que parece haver vicejado no Rio Grande do Sul do período.

$\mathrm{Na}$ realidade, a elite italiana local se manteve realtivamente afastada da Ação Integralista, não por incompatibilidade com a ideologia do movimento, mas para não comprometer a a sua relação com a elite tradicional gaúcha. Do mesmo modo, as classes médias da zona colonial italiana apreciavam positivamente o fascismo italiano e só não aderiram a ele por precisarem de um veículo próprio de expressão (o Integralismo) que superasse os limites oferecidos pelo antigo sistema político do estado (Brandalise, 1992). Não havia, assim, grandes pro-

22 Ver ADA, rolo 2/380, código 832,00, relatório "Integralism, Fascism and Nazism in Rio Grande do Sul and Santa Catarina" do Consulado americano de Porto Alegre ao Departamento de Estado de 9/9/1937 e os comentários deste. O Consulado ressaltava, porém, que não havia um controle italiano ou alemão sobre a ação integralista e nem convergência total de opiniôes e políticas, mas simpatia mútua e colaboração. 
blemas em ser militante fascista e simpatizante do Integralismo ou vice versa. De qualquer modo, um bom estudo local seria interessante para verificar exatamente as ligações e as atividades conjuntas dos fascistas com os integralistas na zona colonial italiana.

Ainda que identifiquemos, porém, que realmente havia divisões de classe e interesses econômicos diversos entre os que apoiavam o fascismo italiano, o Integralismo ou mesmo o antifascismo (o que parece perfeitamente possível), parece fundamental não nos limitarmos a esquemas marxistas excessivamente rígidos e que não incluem fatores além classe, como as diferenças geracionais e de nível de educação, as problemáticas locais e outros, de forma a podermos ter uma visão mais ampla da situação.

Nesse sentido, não só parece ser muito provável, como mencionado, que a divisão entre fascistas e integralistas na região colonial italiana não tenha sido tão forte como se imagina, como a causa dessa divisão parece estar muito mais nas lutas políticas locais (elite fascista e ligada à classe política dominante no estado $\mathrm{X}$ integralistas representando uma classe média de origem italiana desejosa de participação política ${ }^{23}$ ) que numa suposta "luta de classes" entre Fascismo e Integralismo, como quer Corsetti (1986, p. 368).

É impressão do autor, porém, que não só a rede de propaganda e controle do fascismo foi muito menos disseminada no sul que, por exemplo, em São $\mathrm{Paulo}^{24}$, como a adesão formal aos órgãos fascistas foi realmente muito pequena no Rio Grande do Sul, se limitando a alguns poucos membros da burguesia e das classes médias. As causas prováveis para esse fato são a deficiência material da rede de propaganda fascista (e à qual os cônsules e orgãos de propaganda italiana no Rio Grande do Sul nunca paravam de fazer referência) e a própria estrutura social da coletividade italiana no Rio Grande do Sul, onde a ausência dos grandes "capitães da indústria" e de uma classe média mais ampla como em São Paulo ou de uma colônia de comerciantes como as do Nordeste não poderia deixar de ter influência no desenvolvimento dos organismos fascistas..$^{2.5}$

23

24
Para uma excelente análise nesse sentido, ver Brandalise (1992, p. 217-295).

Em 1934, por exemplo, havia apenas sete fasci all'estero no Rio Grande do Sul, contra dezenas em São Paulo. Ver Gagliardetti (1934).

Ver informação textual nesse sentido em AsmAE/Affari Politici 1931-1945 (Brasile), b. 14, p. "Propaganda Culturale 1937", f. 1, relatório do Consulado de Porto Alegre, 25/11/1937. 
Nessa mesma linha de considerações, é visível que outro problema enfrentado pelo fascismo para angariar adeptos na zona colonial gaúcha era o caráter eminentemente rural dessa região. Esse não era, seguramente, um problema único e exclusivo do Rio Grande do Sul (pois a situação se repetia nas zonas rurais paulista e mineira), mas atingiu uma escala maior nessa região onde, segundo fontes fascistas, 80 por cento dos italianos viviam no campo em 1928 (Ministero, 1928, p. 434).

O primeiro obstáculo para a conquista fascista era, obviamente, a dificuldade em se atingir a população rural com a propaganda fascista. Os órgãos fascistas gaúchos se queixavam continuamente, de fato, de como os jornais fascistas não atingiam as populações rurais ${ }^{26}$ e de como era difícil implantar a rede de fasci all'estero, Dopolavoros e etc. no interior do estado. Mesmo a conquista fascista das associações italianas do estado, que teve grande sucesso nas áreas urbanas, pouco efeito podia ter entre as populações rurais, relativamente isoladas e ausentes da vida associativa. ${ }^{27}$

Ao contrário da proposta de Giron de que o fascismo não teve grande interesse em envolver realmente os colonos rurais, pois seria dedicado exclusivamente à burguesia regional (Giron, 1994, p. 114116), acreditamos, a partir do exame da documentação italiana, que o fascismo fez o que pôde para atrair as populações rurais, só não conseguindo uma maior mobilização das mesmas pelas características de vida dessas populações. O máximo que podemos nos aproximar das teses de Giron é aceitar que a população urbana e burguesa era a prioridade da propaganda fascista, o que não implica dizer que os fascistas jamais se dirigissem à população da zona rural.

Nesse sentido, é muito curioso notar que justamente os imigrantes que, no senso comum, deveriam ser os fascistas mais exacerbados (por estarem mais isolados no campo e menos assimilados à cultura brasileira) eram, na verdade, os que menos se interessavam pelo fascismo, pois sua "pureza cultural" era mantida mais por inércia e menos por atos conscientes de defesa da italianidade, enquanto as cama-

\footnotetext{
26 ASMAE/MinCulPop, b. 289, p. "Annuario della Stampa e risposte”, relatório da Embaixada do Rio de janeiro, 9/5/1930.

27 Em 1925, por exemplo, havia 64 associações italianas no Rio Grande do Sul, mas só 16 na zona colonial. Ver Giron, 1994, p. 46-49.
} 
das urbanas mais ricas e assimiladas eram as que aderiam mais fortemente ao fascismo. ${ }^{28}$

Se a questão do ambiente rural teve mais importância no Rio Grande do Sul que em São Paulo, por exemplo, a questão demográfica teve importância similar. De fato, tanto em São Paulo como no Rio Grande do Sul, a coletividade italiana era, nos anos 20 e 30, cada vez mais dominada pelos filhos e netos de italianos ${ }^{29}$ e a substituição dos italianos natos pelos brasileiros de origem italiana não podia deixar de ter efeitos no interesse da coletividade pelo fascismo, o que tanto a documentação italiana $^{30}$ como a americana ${ }^{31}$ não cessavam de recordar, indicando como a questão do fascismo interessava muito mais aos italianos natos que aos filhos de italianos.

O movimento antifascista também sofria das mesmas dificuldades para se afirmar no contexto gaúcho. De fato, o antifascismo sempre foi, apesar da referência a antifascistas em Passo Fundo, Uruguaiana e outros lugares e da existência de grupos antifascistas italianos como o Giacomo Matteotti no final dos anos $20,{ }^{32}$ muito débil no Rio Grande do $\mathrm{Sul}^{33}$ e essa fraqueza é explicável, em boa parte, pela mesma con-

28 Ver para observações análogas para os alemães, Gertz (1987, cap. 3) e Roche (1969, cap. 10).

29 As estimativas do governo americano eram de 95 mil italianos na região sul do Brasil (sendo 80 mil no Rio Grande do Sul) entre 1939 e 1942, com um número de descendentes avaliado em $300 \mathrm{mil} \mathrm{em} 1925$ e algo em torno de 300 a $500 \mathrm{mil} \mathrm{em}$ 1939. Thales de Azevedo (1975, cap. 2) e o governo italiano (Ministero, 1928, p. 464-465) também calculavam em $300 \mathrm{mil}$ os descendentes de italianos no Rio Grande do Sul em 1927. Para os dados americanos, ver ADA, Rolo 4/380, código 832.00F, relatório "Italian Activities in Brazil" de 6/2/1939, fotograma 19, pp. 6368 e NACP/Records of the Office of War Information, RG 208, 208/350/71/12/34, Box 437, relatório "Strategic Survey of South Brazil" de 11/8/1942, section III, paragraph 17.

30 Ver as observações nesse sentido em ASMAE/Affari Politici 1931-1945 (Brasile), b. 14, p. "Propaganda Culturale 1937", f. 1, relatório do Consulado de Porto Alegre, 25/11/1937.

31 ADA, Rolo 4/380, código 832.00F, relatório "Italian Activities in Brazil" de 6/2/1939, fotograma 19 , p. 63-68.

32 Que tinha, porém, apenas 12 membros em 1926 e, não por acaso, ficava em Porto Alegre. Ver ACS/CPC, b. 2352, p. 31962 ("Gherardi, Enrico"), diversos documentos.

33 Em 1928, por exemplo, relatórios do Consulado italiano de Curitiba expressavam a dificuldade dos antifascistas em fazer adeptos nas zonas rurais do Sul, enquanto 
juntura demonstrada anteriormente: falta de um numeroso operariado de origem italiana (tradicionalmente - Bertonha, 1994 e 1994a - o grupo italiano mais sensível ao apelo antifascista) como em São Paulo para servir de base de massas, ${ }^{34}$ falta total de recursos financeiros,,$^{35}$ uma sociedade rural, dominada pelos descendentes de italianos e onde a questão do fascismo/antifascismo não era prioritária etc., o que também limitou as fileiras do antifascismo.

Outra conclusão a que podemos chegar através da documentação e da bibliografia é que os imigrantes italianos recém-chegados (pós 1 Guerra Mundial) tinham muito mais interesse no fascismo e em aderir aos organismos fascistas que os velhos imigrantes, situação que se aproxima do padrão registrado em São Paulo. O fato desses imigrantes recentes serem muito poucos (em todo o Brasil e especialmente no Rio Grande do Sul), também dificultava a tarefa fascista de recrutar adeptos para suas fileiras.

Nesse ponto, abre-se a questão dos "imigrantes tutelados". Loraine Giron (1994, p. 81-83) apresenta esses imigrantes como um grupo de profissionais de alta qualificação que teriam vindo da Itália para a região colonial gaúcha entre 1923 e 1929 com o objetivo de suprir as necessidades de mão de obra da colônia e, a nível subterrâneo, de coordenar e difundir o fascismo localmente.

A autora apresenta a idéia de que esses imigrantes tutelados seguiam um plano geral coordenado e organizado por Roma (o que não é confirmado pelas fontes italianas) e que foram chave na difusão do fascismo nas organizações dos imigrantes, nas cooperativas agrícolas, na imprensa dos centros urbanos, etc. Parece óbvio, de qualquer

em 1942, não só se registram apenas, malgrado o momento favorável (Bertonha, 1997), 55 antifascistas no Rio Grande do Sul como apenas um antifascista (Renzo Rosa) foi receber o Conde Sforza em sua passagem por Porto Alegre em 1942. Ver ACS/CPC, b. 2188, p. 86826, f. 1, diversos documentos; Giron (1994, p. 123-124) e ASmAE/Affari Politici 1931-1945 (Brasile), b. 30, p. "Miscellanea - 1945", carta de Renzo Rosa, 10/8/1944.

${ }^{34}$ Que havia alguns italianos no movimento operário gaúcho (e, especialmente, em Porto Alegre), é fato comprovado. Estavam muito longe, porém, do número e da representatividade dos operários italianos em São Paulo. Ver Borges, 1996.

Os antifascistas não tiveram forças, aliás, para nem mesmo tentar atingir os italianos do campo com algum tipo de propaganda, o que foi feito, por exemplo, na França, onde os antifascistas italianos criaram o jornal L'Attesa para se dirigir aos camponeses italianos da Aquitania. Ver Pistillo, 1995. 
modo, que esses recém chegados foram chave na difusão local do fascismo (ainda mais levando-se em conta suas posições de liderança e prestígio), mas seu pequeno número - uma ou duas centenas de pessoas, segundo a autora (Giron, 1994, p. 81-90) - certamente não poderia fornecer uma base real de massas ao fascismo italiano no Rio Grande do Sul.

É mister ressaltar novamente, porém, que as dificuldades enfrentadas pelo fascismo para recrutar adeptos no Rio Grande do Sul, as quais foram superiores, pelas razões apresentadas, que as encontradas em São Paulo e em outros pontos do país, não significam que o fascismo não tivesse nenhuma popularidade na região colonial italiana, muito pelo contrário.

Loraine Giron vai demonstrar em vários momentos de seu livro, de fato, como uma simpatia generalizada pelo fascismo (não corporificada em adesão formal maciça) atingiu a coletividade italiana do Rio Grande do Sul como um todo, envolvendo igualmente a zona urbana e a rural e atingindo também os descendentes de italianos (Giron, 1994, p. 83-84), no que se aproxima do padrão verificado em São Paulo.

É perfeitamente possível explicar essa popularidade pela questão do resgate do orgulho nacional desses colonos (especialmente nos anos $30,{ }^{36}$ a qual podia levar a grandes momentos de exaltação nacionalista - como a ocorrida em 1935/36, quando a colônia local comemorou festivamente a conquista da Abissínia (Histórias, 1988, p. 2627 e Giron, 1994: 98-100) -, mas que não fornecia a base para a total fascistização dos colonos. ${ }^{37}$ Questões cómo a inédita atenção que o governo de Roma passou a dedicar aos colonos (Giron, 1994, p. 108109) também certamente pesaram.

Na discussão desse tópico, porém, Giron propõe que a questão nacional não era tão importante para explicar essa simpatia pelo fascismo, pois o "amor à pátria e à nação não pareciam ter força junto à comunidade regional, que deixara a Itália no período da organização do Reino, que reunira as pequenas nações que formavam a pátria dos

36 Se o fascismo era relativamente desconhecido na região nos anos 20 , a situação parece mudar radicalmente nos 30. Ver Histórias (1988, p. 34-35).

37 Ver a irritação dos diplomatas italianos com a "passividade" da colônia italiana gaúcha frente ao nacionalismo italiano e o fascismo, a qual só perdia força em "breves parênteses", como a Guerra de 1935/36. Ver ASMAE/Affari Politici 19311945 (Brasile), b. 14, p. "Propaganda Culturale 1937", f. 1, relatório do Consulado de Porto Alegre, 25/11/1937. 
imigrantes" (Giron, 1994, p. 15). Essa questão do relacionamento "identidade regional X identidade italiana" não é, sem dúvida, absurda, mas a própria autora demonstra (Giron, 1994, p. 49-51) como, desde o final do século XIX, a coletividade italiana do Rio Grande do Sul parecia estar reelaborando sua identidade regional em favor de uma identidade italiana (ou, ao menos, de "italianos do Rio Grande do Sul"), o que significa que eles não eram - ainda mais se levarmos em conta que os laços culturais dos mesmos com a Itália ainda existiam, mesmo nos anos 30 -, sem dúvida, imunes ao apelo nacionalista do fascismo.

É uma realidade, contudo, que os italianos da zona colonial gaúcha tinham certas particularidades que merecem destaque. A primeira delas é a persistência de certos valores culturais (trabalho, disciplina, ordem, família) típicos dos imigrantes do norte da Itália (e, especialmente, do Vêneto), os quais podem ter facilitado a popularização do fascismo (Giron, 1986 e 1994, p. 15) e, especialmente, o fortíssimo papel da Igreja Católica na região. ${ }^{38}$

Cumpre ressaltar, de fato, como a área de colonização italiana do Rio Grande do Sul era uma região especial, onde os colonos vênetos e de outras regiões do norte da Itália de forte tradição católica puderam se estabelecer de forma livre e estável e manter suas tradições religiosas. Esta é uma situação completamente diversa da de São Paulo e que permitiu uma imensa influência dos missionários e do clero italianos sobre a coletividade italiana da região. ${ }^{39}$

De forma análoga ao ocorrido em São Paulo e em outras regiões do país, os missionários e os órgãos da Igreja Católica da zona de colonização italiana do Rio Grande do Sul apoiaram decididamente o fascismo, apoiando suas campanhas, trabalhando na difusão de sua ideologia e intervindo com seu poder e influência nas disputas locais, sempre em benefício dos italianos ligados ao regime (Giron, 1994, p. 91-92 e Brandalise, 1992, p. 246-264). Também há registros de uso, pelos fascistas, das organizações católicas para tentar escapar das leis

38 Para uma análise geral da relação dos católicos, brasileiros e italianos, com o fascismo e o Integralismo no Brasil, ver Bertonha (1998).

39 Em São Paulo, a contínua rotatividade dos agricultores nas fazendas, a resistência do clero local e dos fazendeiros e a heterogeneidade dos imigrantes impediu o surgimento de uma influência católica equivalente. Sobre isso, ver Rosoli (1980 e 1982a); Azzi (1990); Favero (1989) e Costa (1987). 
brasileiras de fim dos anos $30,{ }^{40}$ de cartas de padres italianos em atuação em solo gaúchọ endeusando Mussolini e o fascismo ${ }^{41}$ etc. A imprensa católica local também apoiava o fascismo..$^{42}$ Parece óbvia, assim, a ligação do clero italiano com o fascismo no Rio Grande do Sul.

Esse relacionamento não implicava, certamente, numa submissão desse clero aos interesses dos fascistas locais, ${ }^{43}$ mas a realidade é que o raciocínio feito pela esmagadora maioria dos missionários e do clero italiano, e que relacionava catolicismo com italianidade, ${ }^{44}$ se inseria como uma luva nos objetivos fascistas de manter a italianidade dos imigrantes e seus filhos residentes no Rio Grande do Sul via reforço contínuo de seu catolicismo. ${ }^{45}$

Sendo assim e dada também a imensa simpatia ideológica desses religiosos pelo fascismo italiano e pelo Integralismo, ${ }^{46}$ uma aliança era uma conseqüência inevitável que, se não levou a uma fascistização completa dos italianos do Rio Grande do Sul via Igreja (pois esta se recusava a este papel), acabou conduzindo, dado o poder e a influência dela, especialmente entre a população rural, a uma maior preservação da cultura italiana entre essa população e à manutenção de uma forte simpatia difusa com relação ao fascismo que pode ter superado, talvez, aquela registrada, por exemplo, em São Paulo.

40 Ver ACS/MinCulPop, DGP, b. 277, f. 13, sottof. 1, p. "Corsi di lingua e letterattura italiana", Informe do Consulado de Porto Alegre, 28/3/1939 para informações sobre cursos de língua e literatura italianas ocorrendo na Associação dos Professores Católicos para fugir dos problemas com o governo estadual.

41 ASMAE/Affari Politici 1919-1930 (Brasile), b. 905, p. 1642, carta de Padre Luigi Strippoli ao Duce, 21/2/1928.

42 Há registros sobre jornais católicos apoiando o fascismo nas regiôes urbanas e também de filofascismo do importante jornal La Staffeta Rio Grandense, que era dirigido pelos missionários italianos e muito popular entre os trabalhadores rurais. Ver ACs/MinCulPop, DGP, b. 272, f. 10, sottof. 2, p. "La Staffeta Rio Grandense" di Garibaldi”, Informe Consulado de Porto Alegre de 6/6/1934 e Histórias (1988).

43 Ver Rosoli (1980 e 1982a). Para o caso específico da criação da Diocese de Caxias do Sul e as tentativas fascistas, rechaçadas pela Igreja, de interferência direta do Consulado italiano, ver Pinzetta (1995).

44 Ver Rinaldi (1923). Ver também Franzina (1995, p. 230) e Pinzetta (1995).

45 Ver ACs/MinCulPop, DGP, b. 277, f. 13, sottof. 1, p. "Pubblicazioni", informe Consulado de Porto Alegre, 14/4/1938 e ASMAE/Affari Politici 1931-1945 (Brasile), b. 14, p. "Missioni e Missionari - 1937", informe da Embaixada italiana de 11/5/1937 e do Consulado de Porto Alegre de 24/7/1937.

46 Ver Brandalise (1992, p. 217-295). 
De fato, a ausência quase que completa de antifascistas na região colonial $^{47}$ e ação de forças imensamente poderosas (como a Igreja) inexistentes no resto do país em apoio ao fascismo pode ter feito a simpatia difusa dos italianos locais pelo mesmo ser ainda mais forte que no resto do país. Isso levou a um forte apoio dos italianos locais ao Integralismo, que viam nele uma expressão local de um regime - o fascista italiano - que parecia promissor $^{48}$ e que mereceria ser transplantado para o Brasil.

Que a popularidade do fascismo apoiou a difusão do Integralismo e que as ligações entre ambos eram forte arma de propaganda local desse último, é, portanto, ponto passivo. O fato do Integralismo ser um partido através do qual os descendentes de italianos da região colonial podiam se expressar como brasileiros sem romper com a "modernidade" que vinha do país de seus ancestrais também ajudou, sem dúvida (Brandalise, 1992) na sua popularização, restando apenas a questão das possíveis diferenças de "densidade" da conquista integralista entre as classes urbanas das cidades e os colonos rurais. ${ }^{49}$

47 O único caso registrado é D. Luigi Salvetti, escalibriniano e acusado de antifascismo em 1927. Ver ACS/CPC, b. 4552, p. 2268 ("Salvetti, Luigi").

48 De fato, a própria Igreja Católica fazia um raciocínio desse tipo, apoiando a difusão na região colonial italiana tanto do fascismo italiano como do Integralismo e enfatizando a ligação entre os dois movimentos. Ver Giron (1994, p. 95-96) e Brandalise (1992, p. 244). Nesse sentido, o caso gaúcho parece se aproximar muito do dos imigrantes rurais ultra-católicos italianos instalados no Espírito Santo, também fortemente influenciados pelo clero italiano local em direção a posicionamentos pró Fascismo e pró Integralismo. Ver Lazzaro (1992) e Banck (1978). A Ação Integralista também enfatizava, no Rio Grande do Sul, suas pontes com os fascismos europeus, o que não era, certamente, acidental. Ver Brandalise (1992, p. 144-149).

Carla Brandalise (1992) demonstra, como já visto, que as classes médias urbanas da zona colonial eram simpáticas ao fascismo, mas ferrenhamente integralistas, como forma de se diferenciar da elite local e se expressar politicamente, enquanto, entre os colonos rurais, essa perspectiva de integração no contexto sócio político nacional através da AIB estava presente, mas em menor grau e associada a uma maior influência do clero e a uma maior valorização das ligações entre os dois movimentos. Ela indica (1992, p. 289-290) que a penetração do Integralismo foi muito forte também na zona rural, mas parece razoável acreditar que, dado o fascismo mais "difuso" dos colonos e o caráter mais urbano e de classe média do Integralismo, a participação mais densa e efetiva no movimento tenha sido das classes médias urbanas das cidades da zona colonial, especialmente Caxias do Sul. 
A ironia final desse processo foi detectada por Giron (1994, p. 129-137) quando ela afirma que o Estado Novo varguista perseguiu, após 1938, não os verdadeiros fascistas (os ricos burgueses), mas sim os pequenos proprietários rurais que eram só genericamente simpáticos ao fascismo. Não é de se excluir a hipótese de que esse ataque vigoroso à comunidade italiana no Rio Grande do Sul e em Santa Catarina (desconhecido nos outros estados brasileiros - Corsetti, 1990) não tenha sido apenas um reflexo tardio das preocupações com os alemães e os integralistas, mas também um efeito da ascensão política e social das "colônias" dentro da vida gaúcha (Gertz, 1988), o que apenas confirma a necessidade de estudos regionais para captar essas especificidades e a situação particular do Rio Grande do Sul.

\section{Bibliografia citada}

AZEVEDO, Thales de. Italianos e gaúchos: os anos pioneiros da colonização italiana no Rio Grande do Sul. Porto Alegre: A Nação/Instituto Estadual do livro, 1975. AZZI, Riolando. Fé e italianidade: a atuação dos escalabrinianos e dos salesianos junto aos imigrantes". In: DE BONI, Luís A. de (org.). A presença italiana no Brasil. Porto Alegre/Torino: EST/Fondazione Giovanni Agnelli, 1990, p. 63-80. v. 2.

BANCK, Geert Aret. Estratégias de sobrevivência em duas comunidades ítalocapixabas. In: Estudos em homenagem a Ceciliano Abel de Almeida. Vitória: Fundação Ceciliano Abel de Almeida, 1978, p. 65-84.

BERTONHA, João Fábio. La base sociale dell'antifascismo a São Paulo: un'analisi, 1923-1930. In: BLENGINO, Vanni (org.). La riscoperta delle Americhe. Lavoratori e sindacato nell'emigrazione italiana in America Latina, 1870-1970. Milano: Nicola Teti, 1994, p. 390-399.

. Entre burgueses e operários - a representatividade social do antifascismo socialista italiano - São Paulo, 1923-1934. História social, Campinas, v. 1, n. 1, primeiro semestre 1994a, p. 117-144.

Política em tempos de guerra: a tentativa de reconstrução do antifascismo italiano em São Paulo em 1942/43. Revista de História, São Paulo, usP, 137, 1997, p. 43-63.

. A migração internacional como fator de política externa: Os emigrantes italianos, a expansão imperialista e a política exterior da Itália, 1870-1943. Contexto Internacional, 1997 a (no prelo).

. O Brasil, os imigrantes italianos e a política externa fascista, 1922-1943. Revista Brasileira de Política Internacional, v. 40, n. 2, 1997b, p. 106-130.

. Entre a cruz e o fascio littorio: a Igreja Católica Brasileira, os missionários italianos e a questão do fascismo, 1922-1943. História e Perspectivas, Uberlândia, 1998. (no prelo) 
BORGES, Stella. Os italianos e o movimento operário em Porto Alegre. Estudos Ibero-Americanos, v. 22, n. 2, dez. 1996, p. 129-156.

BRANDALISE, Carla. O fascismo na periferia latino-americana: o paradoxo da implantação do Integralismo no Rio Grande do Sul. Dissertação de mestrado em Ciência Política, Porto Alegre, ufrgs, 1992.

CANNISTRARO, Philip. Fascism and Italian americans in Detroit, 1933-1935. International Migration Review, 9, 1975, p. 29-40.

CICCOLELLA, Erasmo. Vibrant life, trenton's italian americans. New York: Center for Mifration Studies, 1986.

CINEL, Dino. Dall'Italia a San Francisco. L'esperienza dell'emigrazione. In: Euroamericani - la popolazione di origine italiana negli Stati Uniti. Torino: Fondazione Giovanni Agnelli, 1987, p. 327-388.

CORSETTI, Berenice. A reação do Estado Novo aos movimentos políticos da zona de colonização italiana no Rio Grande do Sul. História: ensino e pesquisa, 2, 1986, p. 33-54.

- O crime de ser italiano: a repressão do Estado Novo. In: DE BONI, Luís A. (org.). A presença italiana no Brasil. Porto Alegre/Torino: EST/Fondazione Giovanni Agnelli, 1990, p. 363-382. v. 2.

COSTA, Rovílio. Il Contributto del clero italiano alla colonizzazione rio-grandense. In: Scalabriniani tra vecchio e nuovo mondo. Roma, Centro Studi Emigrazione, 1987, p. 411-429.

CRESCIANI, Gianfranco. L'internamento degli italiani nella Nuova Galles Meridionale. In: CRESCIANI, Gianfranco. L'Australia, gli australiani e la migrazione italiana._Milano: Franco Angeli, 1984, p. 81-102.

FAVERO, Luigi. Los Scalabrinianos y los emigrantes italianos en Sudamerica. Estudios Migratorios Latinoamericanos, v. 4, n. 12, ago. 1989, p. 231-256.

FRANZINA, Emílio. Gli italiani al Nuovo Mondo - l'emigrazione italiana in America, 1492-1942. Milano: Mondadori, 1995.

GAGLIARDETTI italiani nel mondo. Novara, 1934.

GERTZ, René. O fascismo no Sul do Brasil - germanismo, nazismo, integralismo. Porto Alegre: Mercado Aberto, 1987.

- Nazismo, fascismo, integralismo e o apoio das oligarquias do Rio Grande do Sul e de Santa Catarina ao Estado Novo. Estudos Ibero-Americanos, v. 14, n. 1, 1988, p. 21-30.

GIRON, Loraine Slomp. As sombras do littorio - o fascismo no Rio Grande do Sul. Porto Alegre: Parlenda, 1994.

GUMINA, Deanna Paoli. The italians of San Francisco, 1850-1930. New York: Center for Migration Studies, 1978.

HARNEY, Robert. Toronto's Little Italy 1885-1945. In: Little Italies in North America, Toronto, 1981.

- La Little Italy di Toronto, 1919-1945. In: Dalla frontiera alle little Italies. Gli italiani in Canada. Roma: Bonacci, 1984, p. 237-260

HISTÓRIAS da Imprensa em Caxias do Sul. Caxias do Sul: Museu Municipal, 1988.

LAZZARO, Antonio et al. Lembranças camponesas: a tradição oral dos descendentes de italianos em Venda Nova do Imigrante. Vitória: Fundação Ceciliano Abel de Almeida, 1992. 
MENEGHETTI, Diane. North Queesland antifascism and the Spanish Civil War. Labour History. n. 42, 1982, p. 63-73.

L'internamento degli italiani nel Queesland Setentrionale. In: Cresciani, Gianfranco. L'Australia, gli australiani e la migrazione italiana. Milano: Franco Angeli, 1984, p. 103-117.

MINISTERO degli Affari Esteri. Censimento degli italiani all'estero alla metà dell'anno 1927. Roma, 1928.

MORMINO,Gary. Immigrants on the Hill: Italian Americans in St. Louis, 1882-1982. Urbana, Chicago: Univ. of Illinois Press, 1986.

, POZZETTA, George. The immigrant world of Ybor City - italians and their latin neighbors in Tampa, 1885-1985. Chicago: University of Chicago Press, 1987.

NELLI, Humbert. The Italians in Chicago, 1880-1930 - A Study in Ethnic Mobility. New York: Oxford University Press, 1970.

O'CONNOR, Desmond. No need to be afraid. Italians settlers in South Australia between 1939 and the Second World War. Kent Town: Wakefield Press, 1996.

PERIN, R. Conflits d'allegiance et d'identit: le propaganda du consulat italien a Montreal dans les annps trente. Questions de Culture - Revue de l'Institute Quebecois de Recherche sur la Culture, v. 1, t. 2, 1981.

PINZETTA, Alvaro Luiz. A criação da Diocese de Caxias do Sul (8-9-1934). In: DE BONI, Luís A. A presença italiana no Brasil. Porto Alegre/Torino: EST/Fondazione Agnelli, 1995, v. 3, p. 534-554.

PISTILLO, Massimo. Coloquio Internazionale sulla presenza degli Italiani in Aquitania (Bordeaux, 12-13 Maggio 1995). Studi Emigrazione, v. 32, n. 19, 1995, p. 538-543.

RAMIREZ, Bruno. Ethnicity on Trial: the italians of Montreal and the Second World War. In: HILLLMER, Norman (ed.). On guard for thee: war, ethnicity and the canadian state, 1939-1945. Ottawa: Ottawa University Press, 1988, p. 71-84.

RINALDI, P. Un nuovo e gravissimo pericolo per i nostri interessi nazionali in Brasile. L'Emigrato Italiano in America, v. 17, n. 3, jul./set. 1923, p. 1-6.

ROCHE, Jean. A colonização alemã e o Rio Grande do Sul. Porto Alegre: Globo, $1969.2 \mathrm{v}$.

ROSOLI, Gianfausto. Le organizzazioni cattoliche e gli emigrati italiani in Brasile. In: DE FELICE, Renzo. L'emigrazione italiana in Brasile (1800-1978). Torino: Fondazione Giovanni Agnelli, 1980, p. 191-233.

- Chiesa ed emigrazione italiana in Brasile, 1880-1940. Studi Emigrazione, v. 19 , n. 66,1982 , p. 225-251.

SCHOR, Ralph. Il fascismo italiano nelle Alpes, 1922-1939. Notiziario dell Istituto Storico della Resistenza in Cuneo, n. 26, dez. 1984, p. 21-56.

- L'image de l'italien dans la France de l'entre deux guerres. In: MILZA, Pierre (ed.). Les italiens en France de 1914 a 1940. Roma: Ecole Française de Rome, 1986, p. 87-109. Collection de l'Ecole Française de Rome, 94.

- 1986a, ibid., p. 576-607.

. Les italiens dans les Alpes Maritimes durant les annes 30. In: TEMINE, Emile (ed.). Gli italiani nella Francia del Sud ed in Corsica (1860-1980). Milano: Franco Angeli, 1988, p. 231-238. 
Les italiens dans les Alpes maritimes au cours des annèes 1930: portrait d'une comunaitè immigrére. In: L'immigration en France dans les années 20. Paris, CEDEI, 1988a, p. 199-209.

— . L image des italiens dans les Alpes Maritimes, 1938-1946. In: Milza, Pierre, PESCHANSKI, Denis. Exils et migration - italiens et espagnols en France, 19381945. Paris: L'Harmattan, 1994, p. 299-311.

SALVETTI, Patrizia. La comunità italiana di San Francisco tra italianità e americanizzazione negli anni 30. Studi Storici, v, 19, n. 65, 1982, p. 3-40.

TRENTO, Ângelo. Do outro lado do Atlântico - um século de imigração italiana no Brasil. São Paulo: Instituto Italiano de Cultura/Nobel, 1989.

ZUCCHI, John. Italians in Toronto. Development of a national identity, 1875-1935. Kingston/Toronto: McGill Queen's University Press, 1988. 